\title{
Estudo Epidemiológico da Esquistossomose Mansônica em Áreas de Irrigação do Nordeste Brasileiro'
}

\section{Epidemiological Study on Mansoni Schistosomiasis in Irrigation Areas of Northeastern Brazil}

\author{
Amaury D. Coutinho' \\ Manoel L. Silva ${ }^{2}$ \\ José F. Gonçalves ${ }^{2}$
}

COUTINHO, A. D.; SILVA, M. L. \& GONÇALVES, J. F. Epidemiological Study on Mansoni

Schistosomiasis in Irrigation Areas of Northeastern Brazil. Cad. Saúde Pübl., Rio de Janeiro, 8 (3): 302-310, jul/set, 1992.

It is acknowledged throughout the world that irrigation is very important in the dissemination of schistosomiasis. The present study, involving 23 irrigation projects in the semi-arid region of five northeastern states of Brazil, was conducted during the period of October 1986 to December 1987.

Socio-economic-sanitary analysis identified a number of aspects of epidemiological importance, mainly the presence of migrant farm workers, coming from endemic areas of schistosomiasis and living in poor sanitary conditions in the irrigation areas. Parasitological exams of stool samples indicated that, out of 10,229 individuals examined ( $82 \%$ of the population), only three were S. mansoni positive. Malacological studies identified Biomphalaria straminea as the only species out of 17,188 snails captured. In only one area (São Gonçalo, district of Souza, Paraiba State), where 3,400 snails were captured, 17 were infected with S. mansoni. These results indicate that, at present, schistosomiasis transmission is not a major problem in the areas studied. However, continued epidemiological surveilance is essential in all irrigation areas of northeastern Brazil if schistosomiasis control is to be maintained. Recommendations are made for improvement in the water supply as well as for additional sanitation measures focusing on migrant workers.

Keywords: Mansoni schistosomiasis; Irrigation; Epidemiology

\section{INTRODUÇÃO}

As áreas de irrigaçāo são mundialmente reconhecidas como importantes focos de transmissão das esquistossomoses (Barbosa, 1978; Bolton, 1988; Chandiwana \& Taylor, 1978; OMS, 1985). Compreendendo esta importância, um grupo de estudiosos brasileiros reuniu-se em Recife, em abril de 1978, para discutir os vários

\footnotetext{
'Realizado com apoio financeiro da Financiadora de Estudos e Projetos (FINEP).

2Centro de Pesquisas Aggeu Magalhäes - Fiocrur. Recife (CPqAM), Departamento de Parasitologia. Campus da Universidade Federal de Pernambuco, Caixa Pastal n' 7472. Recife, 50670-091, PE, Brasil.
}

aspectos da epidemiologia e controle da esquistossomose, sob os auspicios do CNPq (Barbosa, 1978). Este grupo de especialistas, entre várias recomendações sobre o assunto, sugeriu que estudos fossem feitos, sem demora, dada a possível gravidade de expansão da doença nas regiōes semi-áridas do Nordeste, por motivo da construção de barragens e do amplo desenvolvimento dos sistemas de irrigação, no sentido do levantamento da situação da parasitose na região, procurando-se caracterizar os principais elementos que conduzissem a uma ampla visão epidemiológica do problema.

Seguindo esta criteriosa recomendação, o Centro de Pesquisas Aggeu Magalhães/Fiocruz em Recife (CPqAM) empreendeu, no periodo 
de 1979/82, um amplo estudo epidemiológico na área do Nordeste semi-árido compreendendo vários Estados da região (Costa \& Barbosa, 1985; Fundação Oswaldo Cruz, 1982) cujos resultados serão analisados na Discussão comparando com os da presente investigação que se seguiu cinco anos depois na mesma área.

Abordando o tema do impacto do desenvolvimento na expansão da esquistossomose, Camargo (1980) assinala, muito bem, a necessidade de um planejamento inicial sobre a questão de saúde, antes da instalação de represas de cursos d’água para irrigação ou fins hidro-elétricos. Por outro lado, a nova programação do PCE (Programa de Controle da Esquistossomose), antigo PECE, do Ministério da Saúde (Sucam) considera as áreas de irrigação como áreas vulneráveis ou de risco que necessitam de um esquema permanente de vigilância epidemiológica realmente eficaz (Ministério da Saúde, 1988).
Sempre atentos a esta importante problemática, os pesquisadores do CPqAM, decidiram continuar os estudos no semi-árido, promovendo uma reavaliação da permanência ou expansão da esquistossomose nos perímetros de irrigação das áreas previamente estudadas $e$ procurando detectar a possível existência de condições favoráveis à disseminação da doença, no sentido de estabelecer sua prevenção. Os resultados deste estudo são apresentados na presente publicação.

\section{MATERIAL E MÉTODOS}

Foram estudados 23 perimetros de irrigaçāo relacionados ao DNOCS (Departamento Nacional de Obras Contra as Secas) cobrindo os estados de Pernambuco, Paraíba, Rio Grande do Norte, Ceará e Piauí (Tabela 1 e Figura 1).

TABELA 1. Relação das 23 Áreas de Irrigação Estudadas

\begin{tabular}{lll}
\hline \hline Estado & Município & Perimetro \\
\hline Pernambuco & Ibimirim & Moxotó \\
Pernambuco & Custódia & Custódia \\
Pernambuco & Serra Talhada & Cachoeira II \\
Pernambuco & Salgueiro & Boa Vista \\
Paraíba & Condado & Engenho Arcoverde \\
Paraiba & Souza & São Gonçalo \\
Paraíba & Sumé & Sumé \\
Rio Grande do Norte & Caicó & Itans-Sabugi \\
Rio Grande do Norte & Cruzeta & Cruzeta \\
Ceará & Icó & Lima Campos \\
Ceará & Jaguaruana & Jaguaruana \\
Ceará & Iracema & Ema \\
Ceará & Morada Nova & Morada Nova \\
Ceará & Tauá & Várzea do Boi \\
Ceará & Mauriti & Quixabinha \\
Ceará & Forquilha & Forquilha \\
Ceará & Sobral & Aires de Souza \\
Ceará & Pentecostes & Curú Recuperação \\
Ceará & São Luiz do Curú & Curú Paraipaba \\
Piauí & Piripiri & Caldeirāo \\
Piauí & Luzilândia & Lagoa de Piauí \\
Piauí & Cristino de Castro & Gurgueia \\
Piauí & Simplício Mendes & Fidalgo \\
\hline \hline
\end{tabular}


FIGURA 1. Mapa de Distribuição dos 23 Perímetros de Irrigação em 5 (cinco) Estados do Nordeste

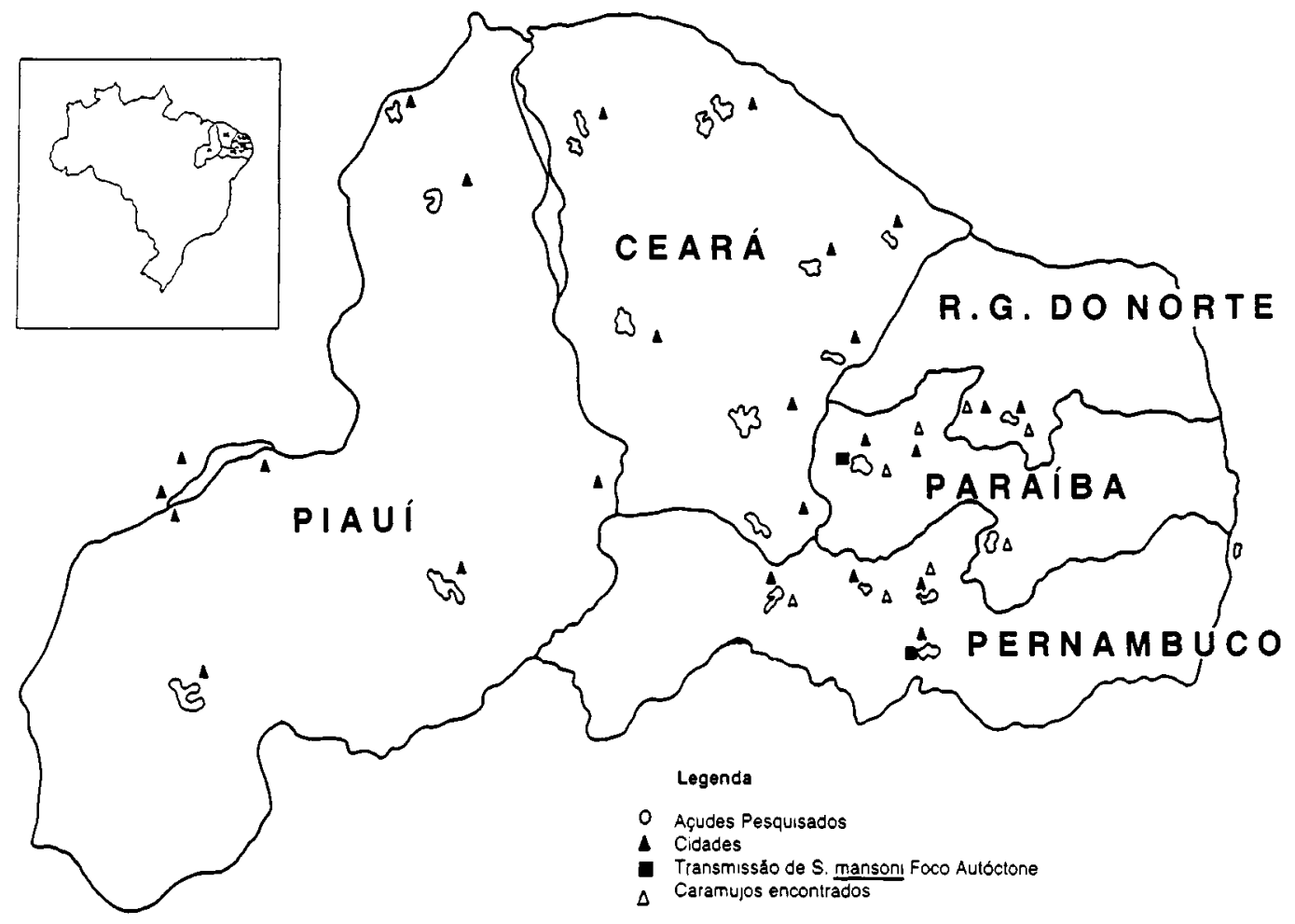

Cada perímetro de irrigação é constituído de agrovilas onde residem os colonos e lotes de irrigação, onde trabalham e desenvolvem suas culturas. Nesses lotes, distantes alguns kilometros das agrovilas, também exercem atividades os trabalhadores rurais contratados pelos colonos para tarefas periódicas de plantio e colheita (pessoal flutuante) e residentes em áreas próximas aos lotes.

Em cada perimetro foram realizadas as seguintes atividades:

1. Estudo da situação sócio-econômica sanitária, pela aplicaçāo de um questionário próprio, em base familiar, por assistentes sociais do DNOCS;

2. Estudo parasitológico de cada colono residente nas agrovilas e de seus familiares, realizado por exame de fezes (uma lâmina) pelo método de sedimentação expontânea de Hoffman, Pons e Janer (Hoffman et al., 1934). As amostras de fezes, colhidas nas agrovilas em recipientes próprios, eram conservadas em solução de MIF (solução de mertiolato, formalina e glicerina) e levadas, alguns dias depois, ao laboratório de parasitologia do CPqAM em Recife. A população flutuante não foi incluída neste estudo.

3. Estudo malacológico em cada área, utilizando a coleta dos caramujos existentes nos criadouros das coleções hídricas (canais de irrigação). Os caramujos coletados eram levados ao laboratório de malacologia do CPqAM para identificação da espécie e pesquisa de infecção pelo $S$. mansoni. Para isto, cada caramujo era exposto ao sol durante uma hora em uma cuba de vidro contendo $5 \mathrm{ml}$ de água desclorada para se verificar a eliminação das cercárias. Trinta por cento dos caramujos negativos eram esmagados em duas placas de vidro superpostas e examinados a lupa para se analisar a presença de esporocistos. 
Este amplo e intensivo trabalho de campo e do laboratório teve a duração corrida de 15 meses, outubro de 1986 a dezembro de 1987. Isto só foi possível porque foram utilizadas as mesmas áreas do estudo anterior que levou três anos e meio (1979/82) (Costa \& Barbosa, 1985; Fundação Oswaldo Cruz, 1982), quando foi realizado todo o levantamento da bacia hidrográfica regional, estudo do censo demográfico e estudo das áreas adjacentes aos perímetros.

\section{RESULTADOS}

1. O estudo da situação sócio-econômicosanitária, revelou os seguintes aspectos:

- As casas das agrovilas são de alvenaria cobertas com telhas, piso de cimento, rebocadas e pintadas com cal. Todas possuem banheiro com água encanada e sanitário com fossa seca;

- A captação da água é quase sempre inadequada, desde que é feita diretamente dos canais de irrigação dos lotes. A água é captada, sem nenhum tratamento e levada a uma caixa elevada construída de cimento para armazenagem e distribuição nas casas. Nos perímetros do estado do Piauí, no entanto, a captação da água é feita diretamente do sub-solo por poço artesiano;

- Cada agrovila é dotada de unidade escolar e cooperativa de produção;

- O sistema de irrigação dos lotes é constituído de canais de irrigação: principais, secundários e terciários. A irrigação é feita sob forma de infltração por gravidade e, em poucos perímetros, também por aspersão;

- Não existem instalações sanitárias nos lotes de irrigação, para uso dos trabalhadores rurais eventuais (pessoal flutuante);

- O número desses trabalhadores é muito variável em cada perímetro e em cada período do ano, em função da intensidade da cultura e produção agrícolas e da época da colheita;

- Em dois perímetros principalmente - Moxotó, em Pernambuco e São Gonçalo, na Paraíba, esses trabalhadores residiam em áreas bem próximas aos lotes de irrigação, em cujas áreas se constatou, no estudo anterior, (Costa \& Barbosa, 1985; Fundação Oswaldo Cruz, 1982) presença de portadores de esquistossomose.
2. O estudo parasitológico é mostrado na Tabela 2 em relação à positividade para $S$. mansoni na população de cada perímetro. É interessante assinalar que $82 \%$ da população total dos vários perímetros forneceu material para exame coprológico. Apenas três casos foram positivos para $S$. mansoni (perímetros de Moxotó, engenho Arcoverde e São Gonçalo), os quais estão referidos na Tabela 3. Dois deles, originários de Moxotó e de Engenho Arcoverde, foram considerados casos autóctones por terem nascido e permanecido nos perímetros respecticos.

A Tabela 4 mostra o sumário dos resultados positivos para outras helmintoses e protozooses intestinais encontradas no conjunto dos 23 perímetros, por ordem de prevalência de cada parasitose. A maior prevalência foi constatada pos perímetros de Pernambuco e Paraíba e a menor nos do Ceará e Piauí.

3. O estudo malacológico indicou, inicialmente que todos os caramujos encontrados nos diferentes criadouros eram da espécie Biomphalaria straminea. A Tabela 5 mostra o número de moluscos encontrados em cada área e a respectiva positividade para infecção com $S$. mansoni. Apenas em uma área (São Gonçalo, PB) foram constatados caramujos infectados $(0,5 \%)$. Como de esperar, houve predominância de caramujos nos perímetros localizados nos Estados de Pernambuco e Paraíba, sendo que em alguns perímetros dos Estados do Ceará e Piauí nenhum molusco foi encontrado.

O foco de caramujos infectados em S. Gonçalo estava localizado no canal principal de irrigação, utilizado pelos trabalhadores flutuantes para banho e lavagem de roupa e, como soe acontecer, levando-os a defecação próxima e, em consequiencia, a instalação do referido foco. Como o mesmo era distante da moradia dos colonos e, possivelmente recente, não houve oportunidade de contaminação destes. Uma vez diagnosticado o foco de caramujos, o mesmo foi notificado as autoridades da Sucam-PB que tomaram as providências cabiveis. Em uma segunda visita a área, 6 meses após, os autores verificaram a extinção do foco mencionado.

\section{DISCUSSÃO}

O presente estudo (1986-1987), realizado em 
TABELA 2. Resultado Parasitológico em Relação a Positividade para S. mansoni nos 23 Perímetros Estudados

\begin{tabular}{lcc}
\hline \hline Perimetro & $\begin{array}{c}\text { No de Pessoas } \\
\text { Examinadas }\end{array}$ & $\begin{array}{c}N^{2} \text { de Casos } \\
\text { Positivos }\end{array}$ \\
\hline Moxotó - PE & 1963 & 01 \\
Custódia - PE & 376 & - \\
Cachoeira II - PE & 164 & - \\
Boa Vista - PE & 263 & - \\
Engenho Arcoverde - PB & 313 & 01 \\
São Gonçalo - PB & 2192 & 01 \\
Sumé - PB & 304 & - \\
Itans-Sabugi - RN & 466 & - \\
Cruzeta - RN & 287 & - \\
Lima Campos - CE & 906 & - \\
Jaguanuana - CE & 266 & - \\
Ema - CE & 115 & - \\
Morada Nova - CE & 916 & - \\
Várzea do Boi - CE & 103 & - \\
Quixabinha - CE & 275 & - \\
Forquilha - CE & 176 & - \\
Aires de Souza - CE & 135 & - \\
Cuni Recuperação - CE & 102 & - \\
Curú Paraibana - CE & 141 & - \\
Caldeirão - PI & 245 & - \\
Lagoa do Piauí - PI & 190 & - \\
Gurgueia - PI & 235 & - \\
Fidalgo - PI & 145 & - \\
\hline Total Coletado & $10.279^{*}$ & 03 \\
\hline \hline
\end{tabular}

* Este número representa $82 \%$ da população residente estimada.

TABELA 3. Casos Positivos para o S. mansoni

\begin{tabular}{lccllc}
\hline \hline Iniciais & $\begin{array}{l}\text { Idade } \\
\text { (anos) }\end{array}$ & Sexo & Perímetro & $\begin{array}{l}\text { Local de } \\
\text { Nascimento }\end{array}$ & $\begin{array}{l}\text { Tempo de } \\
\text { Permanência no } \\
\text { Perímetro (anos) }\end{array}$ \\
\hline L. S. & 08 & M & Moxotó, PE & Moxotó & 08 \\
L. G. & 15 & F & Eng. Arcoverde, PB & Condado & 13 \\
A. L. S. & 45 & M & São Gonçalo, PB & - & 09 \\
\hline \hline
\end{tabular}

23 perimetros de irrigação do nordeste semiárido relacionados ao DNOCS (Estados de Pernambuco, Paraíba, Rio Grande do Norte, Ceará e Piaun) somente constatou três casos positivos para $S$. mansoni dentre 10.279 indivíduos examinados. Esses casos estavam localizados nos perimetros de Moxotó (Município de Ibimirim, PE), São Gonçalo (Souza, PB) e Engenho Arcoverde (Condado, $\mathrm{PB}$ ), um pacien- te em cada perímetro, os quais foram tratados com oxamniquine.

No tocante ao estudo malacológico, somente um perímetro (São Gonçalo, Souza, PB) apresentou 17 caramujos infectados por $S$. mansoni dentre 3.400 caramujos examinados (B. straminea), indicando a presença de um foco de transmissão da parasitose.

A aparente disparidade entre a presença de 
um foco com 17 caramujos infectados e a constatação de um único caso humano da parasitose em colonos residentes na área, pode ser explicada por tratar-se possivelmente de um foco recente, originário da contaminação por trabalhadores flutuantes e não utilizado pelos colonos. O referido foco foi depois extinto pelo pessoal da Sucam, pelo que pode ser considerado como foco episódico.

Todavia, este fato deve servir de alerta para possivel formaçāo de focos semelhantes nesta área ou em outras equivalentes, pela utilização dos canais de irrigação por trabalhadores eventuais provenientes de zonas endêmicas próximas, e desta forma, expandir a transmissão da endemia.

É de interesse referir que no estudo anterior (1979-82) (Costa \& Barbosa, 1985; Fundação Oswaldo Cruz, 1982) realizado pelo CPqAM nos mesmos 23 perímetros de irrigação, as áreas de Moxotó (PE) e São Gonçalo (PB) foram as únicas consideradas áreas problemáticas com vários casos humanos positivos (16 em Moxotó e $146 \mathrm{em}$ São Gonçalo) todos posteriormente tratados pela Sucam com oxamniquine. contudo, nesse estudo o levantamento malacológico nos dois perímetros foi negativo, ao contrário do presente estudo.

Essas constatações levam a considerar que estas duas áreas, assim como os perimetros de irrigação de um modo geral, devem ser mantidos em regime de vigilância epidemiológica no tocante a esquistossomose. Ferreira filho, em trabalho antigo (Ferreira Filho, 1975/76), já chamava a atenção para o perigo de constituírem focos de esquistossomose os projetos de irrigação que se pretendiam instalar nas várzeas inundáveis do Baixo São Francisco através da Codevasp. Em relação a esta, convém ressaltar os grandes projetos de irrigação já instalados (ex.: Projeto Bebedouro) ou em desenvolvimento (ex.: Projeto Nilo Coelho) que necessitam uma urgente abordagem epidemiológica relativa a esquistossomose.

$\mathrm{Na}$ verdade, aquelas mesmas áreas já foram consideradas áreas problemas em periodo pregresso (1972-1973) com 32 pacientes em Moxotó e 241 em São Gonçalo, tratados posteriormente pela Sucam (Freitas, 1988). Ambos perímetros apresentam maior contingente de trabalhadores flutuantes, originários de áreas próximas e endêmicas de esquistossomose, os quais devem ser os responsáveis pela presença, já antiga, da infecção nos referidos perímetros. Alguns dos casos diagnosticados em crianças e adolescentes nessas áreas, nos dois estudos, foram considerados casos autóctones tendo adquirido a infecção em focos locais já instalados.

A propósito destes trabalhadores flutuantes, contratados periodicamente nas épocas de plantio e colheita, a sua situação sanitária constitue o ponto mais vulnerável da análise sócio-econômica-sanitária do presente estudo e do anterior (Costa \& Barbosa, 1985; Fundação Oswaldo Cruz, 1982) desde que não existem facilidades (latrinas e fossas) no campo, aspecto que necessita de uma urgente abordagem, objetiva e prática, por parte das autoridades (centrais e regionais) em saúde e em agricultura.

Pelo que foi verificado nestes dois estudos, realizados pelos técnicos do CPqAM (1979-82 e 1986-87) podemos inferir que a infecção por S. mansoni nos perímetros de irrigação, embora limitada, ocorre particularmente nos campos de cultura e não em torno das habitações como é habitual nas regiões endêmicas do nordeste (focos peridomiciliares).

De qualquer forma, a baixa suscetibilidade do transmissor local que costuma ocorrer, geralmente, em áreas mais recentes de introdução da doença, no caso a regiāo semi-árida, associada às condições sanitárias existentes nos perímetros de irrigação, ora descritas que não conduzem, habitualmente, a população fixa à poluição fecal dos canais de irrigação - são possivelmente os principais fatores desfavoráveis da implantação da esquistossomose nessas áreas.

Esta constatação favorável, ao contrário do que se poderia esperar por dados de outros países (OMS, 1985), tem correspondència em um estudo antigo realizado em uma área limitada do Município de Petrolândia, PE (núcleo Codevasp) (Costa, 1978) e em um estudo recente feito em Camarões, na África em áreas de irrigação de arroz onde foi constatada que a prevalência da esquistossomose (e da malária) permaneceu constante em um período de 6 anos (Audibert et al., 1990).

$E$ interessante referir que no estudo anterior (1979-1982), a situação dos grandes lagos 
TABELA 4. Prevalência de Outras Helmintoses e Protozooses Intestinais Encontradas nos 23 Perímetros (\%)

\begin{tabular}{lcc}
\hline \hline Parasito & $\begin{array}{c}\text { Prevalência } \\
\text { Média }\end{array}$ & Valores Limites \\
\hline Ascaris lumbricoides & 13,5 & $0,6-36,9$ \\
Giardia lamblia & 11,8 & $3,3-17,9$ \\
Ancilostomídeos & 7,7 & $0,3-20,6$ \\
Hymenolepis nana & 4,2 & $0,1-12,3$ \\
Strongyloides stercoralis & 1,3 & $0-8,1$ \\
Trichuris trichiura & 1,1 & $0-3,9$ \\
Enterobius vermicularis & 0,5 & $0-1,4$ \\
Taenia s. p. & 0,4 & $0-1,5$ \\
Entamoeba histolytica & 0,6 & $0-1,1$ \\
\hline \hline
\end{tabular}

TABELA 5. Resultado Malacológico em Cada Perímetro

\begin{tabular}{lrl}
\hline \hline Perímetro & $N^{2}$ de Caramujos Examinados & Positivos p/ S. mansoni \\
\hline Moxotó - PE & 1632 & Negativo \\
Custódia - PE & 550 & Negativo \\
Cachoeira II - PE & 1580 & Negativo \\
Boa Vista - PE & 611 & Negativo \\
Engenho Arcoverde - PB & 251 & Negativo \\
São Gonçalo - PB & 3400 & Positivo 17 (0,5\%) \\
Sumé - PB & 410 & Negativo \\
Itans-Sabugí - RN & 694 & Negativo \\
Cruzeta - RN & 915 & Negativo \\
Lima Campos - RN & 2862 & Negativo \\
Jaguaruana - CE & 704 & Negativo \\
Ema - CE & 611 & Negativo \\
Morada Nova - CE & 623 & Negativo \\
Várzea do Boi - CE & 1350 & Negativo \\
Quixabinha - CE & encontrado & \\
Forquilha - CE & Não encontrado & \\
Aires de Souza - CE & Não encontrado & \\
Curú Recuperação - CE & 316 & Negativo \\
Curú Paraipaba - CE & Não encontrado & \\
Caldeirão - PI & 190 & Negativo \\
Lagoa do Piauí - PI & 472 & Negativo \\
Gurgueia - PI & Não encontrado & \\
Fidalgo - PI & Não encontrado & \\
\hline Total Coletado & 17.188 & $17(0,1 \%)$ \\
\hline \hline
\end{tabular}


e barragens da região (Sobradinho e Boa Esperança) foi considerada satisfatória, não tendo sido detectada infecção esquistossomótica nos mesmos. No atual estudo, não foi possível examinar os referidos lagos e as populações circunvizinhas.

A prevalência de outras helmintoses e protozooses intestinais nos 23 perímetros foi baixa, predominando, entre as primeiras, o Ascaris lumbricoides (média de 13,5\%) e, entre as segundas, a Giardia lamblia (média de 11,8\%). Os perímetros dos Estados de Pernambuco e Paraíba apresentaram maior prevalência e os dos Estados do Ceará e Piauí, os menores percentuais.

Embora os resultados do presente estudo tenham sido altamente satisfatórios no sentido de não identificar, no momento, expansão da esquistossomose nos 23 perímetros de irrigação do nordeste semi-árido abrangidos pelo DNOCS, julgamos importante uma permanente vigilância epidemiológica nessas áreas de irrigação em todo o nordeste, ligadas ao DNOCS e a Codevasp que devem ser consideradas, no Programa de controle da esquistossomose, como áreas de risco ou áreas vulneráveis organizadas (Sucam) (Ministério da Saúde, 1988). Neste sentido, é altamente recomendável um perfeito entrosamento entre os órgãos governamentais de âmbito central e regional a exemplo do Ministério da Agricultura (Secretaria Nacional de Irrigação), Ministério da Saúde (Fundação Nacional de Saúde, Fiocruz/ CPqAM), Sudene e Secretarias de Saúde dos Estados envolvidos. Estudos devem ser conduzidos por todos os setores integrados, no sentido de determinar os melhores métodos de irrigação para as diferentes culturas agricolas $\mathrm{e}$ as diferentes condições ambientais e econômico-financeiras, que levem em conta, também, o menor risco de contaminação da água e de proliferação dos caramujos transmissores da esquistossomose.

Estas medidas devem abranger os sistemas de captação e tratamento da água mais adequados e econômicos, a construção de fossas e latrinas comunitárias nos lotes, já mencionadas anteriormente e as técnicas de engenharia mais apropriadas (Bolton, 1987). tudo isso, sem esquecer a educação em saúde no sentido amplo e, especificamente, visando a prevenção da in- feç̧ão esquistossomótica e das outras infecções de veiculação hídrica ou de contaminação pelo solo. Em cada perímetro de irrigação deverá, então, existir um Posto de Saúde com a presença permanente de um agente de saúde ou auxiliar de enfermagem, sob supervisão periódica de um médico.

E de interesse registrar aqui que na Lei $\mathbf{n}^{2}$ 6.662 de 25 de junho de 1974 que dispõe sobre a política nacional de irrigação (Brasil, 1979), o Parágrafo Único do Art. $2^{\circ}$ determina:

"O regime do uso de águas e solos para fins de irrigação, obedecerá aos seguintes princípios:

$V$ - Observância das normas de prevenção de endemias nurais e de salinização dos solos, bem como a preservação do meio ambiente e da boa qualidade das águas".

Falta somente, para que a coisa funcione, a observância rigorosa da Lei e a existência e cumprimento de normas complementares por parte dos setores responsáveis da administração pública.

\section{RESUMO}

COUTINHO, A. D.; SILVA, M. L. \& GONÇALVES, J. F. Estudo Epidemiológico da Esquistossomose Mansônica em Áreas de Irrigação do Nordeste Brasileiro. Cad. Saúde Públ., Rio de Janeiro, 8 (3): 302-310, jul/set, 1992.

É mundialmente reconhecida a importância das áreas de irrigação na disseminacão da esquistossomose. $O$ presente estudo foi desenvolvido no período de outubro de 1986 a dezembro de 1987 em 23 perímetros de irrigação do Nordeste semi-árido. A análise sócio-econômica-sanitária mostrou vários aspectos de interesse epidemiológico, salientando-se a presença de trabalhadores flutuantes originários de áreas endêmicas da parasitose e vivendo em más condições sanitárias nos lotes de irrigação. O estudo coprológico indicou os seguintes resultados: de 10.279 individuos examinados $(82 \%$ da 
população) somente 3 (três) casos apresentaram-se positivos para $S$. mansoni. $O$ estudo malacológico mostrou a presença exclusiva da Biomphalaria straminea em 17.188 amostras coletadas. Somente em um dos perímetros (São Gonçalo, Souza, PB) foi constatada a infecção esquistossomótica ativa em 17 caramujos. Esses resultados indicam que as áreas de irrigação estudadas não constituem, no momento, problema relevante de transmissão da esquistossomose. Os autores consideram, porém, necessária uma permanente vigilância epidemiológica em todas as áreas de irrigação do Nordeste.

Palavras-Chave: Esquistossomose Mansônica; de Irrigação; Epidemiologia

\section{REFERÊNCIAS BIBLIOGRÁFICAS}

AUDIBERT, M.; JOSSERAN, R.; JOSSE, R. \& ADJIDJI, 1990. Irrigation, schistosomiasis and malaria in the Logone Valley, Cameroon. American Journal of Tropical Medicine and Hygiene, 42: $550-560$.

BARBOSA, F. S. (Coord.), 1978. Epidemiologia e controle da esquistossomose e o Nordeste semiárido; relatório de Grupo de Trabalho. Brasilia: CNPq.

BONTON, P., 1987. Schistosomiasis: engineering controls. ODU Bulletin, 7: 47.

BOLTON, P., 1988. Schistosomiasis control in irrigation schemes in Zimbabwe. Journal of Tropical Medicine and Hygiene, 91: 107-114.

BRASIL, 1979. Lei $\mathrm{n}^{\circ} 6662$, de 25 de junho de 1979. Dispóe sobre Politica Nacional de Irrigação e dá outras providências. Diário Oficial (da República Federativa do Brasil), 177: 8937 8941, 26 de jun. 1979. Seção 1 pt. 1.
CAMARGO, S., 1980. Impacto do desenvolvimento na expansão da esquistossomose. Revista do Instituto de Medicina Tropical de São Paulo, 22: 117-119.

CHANDIWANA, S. K. \& TAYLOR, P., 1987. Schistosomiasis control and monitoring in Zimbabwe. ODU Bulletin, 7: 8-10.

COSTA, D. P. P., 1978. Estudo epidemiológico da esquistossomose em área de irrigação do sertão de Pernambuco. Revista da Fundaçāo SESP, 23: 9-14.

COSTA, D. P. P. \& BARBOSA, F. S., 1985. A esquistossomose e o Nordeste semi-árido. I. $O$ estudo preliminar. Cadernos de Saúde Pública, 1: 153-159.

FERREIRA FILHO, J. L., 1975/76. Binômio esquistossomose-irrigação e as várzeas inundáveis da bacia do São Francisco. Associação da Faculdade de Medicina da Universidade de Minas Gerais, 32/33: 39-47.

FREITAS, C. A., 1988. História da peste e de outras endemias. Rio de Janeiro: PEC/ENSP.

FUNDAÇÃO OSWALDO CRUZ. Centro de Pesquisas Aggeu Magalhães, 1982. Epidemiologia $e$ controle da esquistossomose do Nordeste semiárido; relatório final 79/82. Recife.

HOFFMAN, W. A.; PONS, J. A. \& JANER, J. L., 1934. Sedimentation concentration method in schistosomiasis mansoni. Puerto Rico Journal of Public Health and Tropical Medicine, 9: 283289.

MINISTÉRIO DA SAÚDE. Superintendência de Campanhas de Saúde Pública, 1988. Normas gerais para o Programa de Controle da Esquistossomose. Brasilia: Ministério da Saúde.

ORGANIZACION MUNDIAL DE LA SALUD, 1985. Control de la esquistosomiasis: informe de un Comite de la OMS. Genebra: OMS. (Série de Informes Técnicos, 728). 